\title{
Risk Factors for Neonatal Morbidity and Mortality: Empowering the Adolescent Mothers through Evidence Based Health Education, Busia County Referral Hospital
}

\author{
Anne Wawire Kabimba*, Emmah Matheka, Sabina NM Wakasiaka
}

School of Nursing Sciences, University of Nairobi

\section{*Corresponding Author}

Anne Wawire Kabimba

\section{Article History}

Received: 03.05.2020

Accepted: 25.05 .2020

Published: 29.06.2020

\begin{abstract}
Background: Statistics show that, neonatal mortality (NNM) accounts for approximately $40 \%$ of the under-five mortality globally. The risk factors are varied but cut across all nations. The purpose of this study was to empower the expectant adolescent mothers through 'evidence-based health education' hence reduce NNM. The study objectives were; to identify, describe and find solutions to the risk factors through health education. Methods: the study was carried out at Busia County Referral Hospital (BCRH), Western Kenya using a cross-sectional interventional design. 226 expectant adolescent mothers attending the antenatal clinic were randomly sampled. Expectant adolescent mothers aged $\leq 19$ years, $26-34$ weeks gestation and residents of Busia County were selected. Mothers with co-morbidities, students and non -Kenyans were excluded. Ethical approvals from KNH/UONREC, BCRH; Director of Health, County Government of Busia were obtained. Data was collected using semi-structured researcher -administered questionnaires. Analysis utilized Epi Data 3.1, STATA version 8.0, Microsoft excel and reported in frequencies and percentages. Intervention: respondents were grouped in 20s of same gestation. A pragmatic approach was used to cushion respondents from making many trips to the hospital. The sessions were conducted by the researcher who after each overview, allowed respondents to share experiences. Results: risk factors identified; lack of knowledge-84.5\%, poor infrastructure-83.6\%, negligence- $81 \%$ non-breastfeeding- $80.1 \%$, lack of emphasis on neonatal care by the community$77 \%$ and prematurity-67.3\%. $87 \%$ of the respondents applauded the intervention. Discussion: the respondents expressed desire for neonates to be recognized and valued at home. Conclusion: risk factors that contributed to NNM were of duo play, involving respondents and the community. This revealed gaps in information acquisition, awareness and neonatal care practices. Recommendation: there is need for space and age- specific care tailored to adolescent mothers and the need to step -up and intensifies health education strategies.
\end{abstract}

Keywords: NNM, adolescent mothers, risk factors, health education.

\section{INTRODUCTION}

The risk factors to neonatal morbidity and mortality cut across all nations. However, a few factors are specific to regions depending on the geographical, historical, economic, cultural and social makeup. While in the health institution set up, such factors are attributed to preterm birth which contributes to the highest mortality, low birth weight of less than $2500 \mathrm{~g}$, birth asphyxia, birth trauma, severe birth defects and lack of adequate resources and equipment to handle neonatal emergencies [1], in Busia, the adolescent mothers' viewpoint approves such factors as; neonatal sepsis, poor socioeconomic status, poor infrastructure, cultural beliefs, traditions and practices, neonatal negligence, lack of knowledge, non-breast feeding/poor neonatal feeding habits and malnutrition among others.

Adolescent mothers' health education seems to have been entangled in adolescent health projects. For this reason, the specific needs of the expectant and nursing adolescent mothers were not adequately addressed leading to inadequate information and misconceptions.

Copyright @ 2020: This is an open-access article distributed under the terms of the Creative Commons Attribution license which permits unrestricted use, distribution, and reproduction in any medium for non commercial use (NonCommercial, or CC-BY-NC) provided the original author and source are credited. 


\section{Purpose of the Study}

The purpose of this study was to empower the expectant and nursing adolescent mothers to manage the risk factors attributed to neonatal morbidity and mortality within their means. This was achieved through small group interactive sessions guided by the researcher. The topics to be taught were pre-determined and tailored towards helping the adolescent mothers to understand how they could reduce or prevent neonatal illnesses and deaths. This health education was not only meant to help the adolescent mothers realize their full potential but also play their important motherhood roles in the reduction of neonatal morbidity and mortality.

\section{Significance of the Study}

It was necessary for this kind of study to be carried out in Busia in order to empower this unique group of mothers who have gone unrecognized for decades and instead treated like the older mothers. During health education, these mothers were handled in ways compatible to their age and level of understanding as compared to earlier days before the study when all expectant women were treated the same regardless of the age. This enabled the adolescent mothers to comprehend the information given and reason out their ways, made informed decisions, choices and took appropriate constructive actions without relying on others.

\section{Justification}

For a long time, expectant mothers were treated as passive learners and listeners to a health care provider narrating to them the 'dos' and 'don'ts' of pregnancy, child birth, newborn and postnatal care. The adolescent mothers, given the short concentration span, did not get the message, leave alone using it. As to whether there was any follow up of these mothers, pre- and post-childbirth, remains unknown. In this study, this group of mothers was curved off from the rest of the mothers for purposes of ensuring understanding and use of the information shared, follow up and adequately addressing their unique unmet needs.

\section{Study Objectives}

1. To identify and describe risk factors that predispose to morbidity and mortality among neonates born to adolescent mothers in BCRH.

2. To empower the expectant and nursing adolescent mothers through evidence-based health education

3. To evaluate the effectiveness of the health education intervention.

The beneficiaries of the findings of this study comprised all the stakeholders. For example; adolescent mothers learned critical thinking and decision-making skills and as such were able to exercise their potential and take up their motherhood roles. There was improved neonatal care from the health fraternity. Documentation that looked general would be much easier within a system that is specific in record keeping. There would be reduced neonatal morbidity and mortality rates as awareness on risk factors will have helped the mothers care for the neonates better.

\section{LiTERATURE REVIEW}

Globally, many researchers have found out that risk factors responsible for neonatal morbidity and mortality are either i). Maternal -related; non-breastfeeding, maternal malnutrition, maternal co-morbidities, neonate abandoning and negligence ii). Neonate- related; prematurity, low birth weight, congenital abnormalities, birth asphyxia, birth trauma, poor feeding habits iii). Health care provider/facility -related; poor neonatal resuscitation practices, lack of equipment and resources to handle neonatal emergencies and extremely premature neonates and iv). Community- related; cultural beliefs and practices [2-9]. Almost all articles, studies and reports came up with similar or same risk factors though not maternal age specific. According to Abdullah, et al. [10], their study in Indonesia reported six main factors associated with higher risk of neonatal deaths; neonatal complications during birth, neonatal infections, maternal lack of knowledge of neonatal danger signs, low apgar scores, home births and maternal antenatal complications. Birju \& James [11] in their study indicated that neonatal sepsis immensely contributed to neonatal morbidity and mortality, especially among neonates with extreme low birth weight. According to Hibstu, et al. [12], the major determinants of neonatal morbidity and mortality were lack of knowledge, low level of education, traditional and cultural influence, inaccessible and poor health facilities.

In Africa, neonatal morbidity and mortality has been associated with similar risk factors as those identified by WHO and other researchers. In addition, poor maternal health during pregnancy, poverty, lack of information, neonatal infections, low education levels and stigma among others have been implicated [13]. Neonatal care practices cut across all African countries with minimal differences. A study in Malawi reported the same risk factors as indicated above [13] and in addition blamed the high incidences of neonatal infections due to ignorance. In Tanzania, a study conducted by UNICEF [14] indicated that the high neonatal mortality rate was attributed to the same risk factors mentioned above and in addition maternal co-morbidities, lack of knowledge and poor neonatal care practices and health seeking behaviors were implicated [15]. Studies in Uganda reported similar risk factors and in addition, poverty, lack of knowledge, high 
prevalence of malaria, low education standards, household food insecurity, poor infrastructure, inability/delays to access health care were cited as key factors [16]. This was echoed in reports by WHO 2017, 2018.

In Kenya, neonatal mortality rate among mothers aged below 20 years was 27 vs 21 in the above 20 age group in 2014 [17] compared to national rate of 22. Of these, two-thirds occurred during the first seven days of life [18] mostly due to prematurity and sepsis. Furthermore, socioeconomic factors, cultural beliefs and traditions, lack of knowledge, low education standards, community laxity and household food insecurity, inability to access health care, harsh parents or guardians, poor infrastructure were cited as key factors that played a major role in neonatal morbidity and mortality. This ranked Kenya 145/172 of the countries that have made efforts to reduce neonatal morbidity and mortality [20].

In Busia County, the risk factors included all of the above plus mothers abandoning and /or neglecting their neonates. Neonates were cared for by the adolescent's grandmothers or otherwise terminated their pregnancies in the late $2^{\text {nd }}$ or early $3^{\text {rd }}$ trimesters leading to premature births. The other factors were community instigated as communities did not value neonatal health [21] and as such did not or delayed to seek medical help. First line treatment of choice for the ill neonate was tradition-oriented. This caused toxicity and probable substance poisoning to the neonates leading to death. The poor infrastructure, births by unskilled care providers and the poor environmental hygiene were all implicated. Low levels of education, inadequate knowledge and poor social support systems have also been attributed to increased neonatal morbidity and mortality [22].

\section{METHODS}

The study was carried out at Busia County Referral Hospital in Western Kenya. The prevalence of neonatal morbidity and mortality was $58 \%$ at the start of the study for the adolescent mothers for the past three years as per the demographic survey reports against $33 \%$ in the general population.

\section{Study Design}

A cross-sectional interventional study design was employed because of the nature of the research. Study population comprised expectant mothers attending antenatal clinic at Busia County Referral Hospital. Target Population comprised expectant adolescent mothers aged 19 years and below, attending the antenatal clinic at BCRH.

\section{Sampling Technique}

Simple random with replacement

\section{Inclusion Criteria}

For a respondent to be included in this study, she must be aged19 years or below, be expectant at a gestation of 26-34 weeks and a resident of Busia County.

\section{Exclusion Criteria}

The respondents who did not meet the above set criteria were not selected. Additionally, adolescent expectant mothers with chronic co-morbidities on regular medication, students and/or non-Kenyans were excluded.

\section{Sampling Procedure}

The technique was based on a single sequence of random assignment since all respondents had an equal chance of participating in the study. A total of 264 expectant adolescent mothers were recruited but reduced to 226 after data cleaning as some questionnaires had errors.

Materials: The questionnaire was semi-structured developed by the researcher and verified by the statistician. It was fairly easy and short, taking approximately 5-8 minutes. The questionnaires were administered to the selected respondents every day for fifteen (15) days at a rate of 15 respondents per day. The respondents were divided into groups of twenty members based on gestation period and led through guided health education sessions by the researcher. The researcher taught the selected topics after which, the respondents were allowed to share experiences. This promoted ownership of the issues hence the desire to counteract them in their own possible ways. The respondents were followed up individually with the assistance of community health volunteers to ensure what was discussed during the health education sessions was being practiced.

\section{Implementation of the Intervention}

The health education sessions were carried out at the hospital. Each session took at most one and half hours including routine antenatal checkup. The topics taught included; importance of antenatal care, danger signs, nutrition, personal hygiene, exercises, birth preparedness and complication readiness. Labour: signs of true labour, when to seek medical help and childbirth. Post childbirth: care of the neonate, exclusive breast feeding, baby immunizations, decision making skills, problem ownership, solving skills and copying mechanisms. 


\section{Procedure of intervention implementation}

Topic: Risk factors associated with neonatal morbidity and mortality among neonates born to adolescent mothers in Busia County Referral Hospital.

Lesson objectives: i). Identify and explain the risk factors. Ii). Describe the mitigation measures.

\section{Variables addressed}

\section{- Predisposing factors}

Characteristics that affect behavior and ability in decision-making; knowledge, cultural beliefs, maternal comorbidities, genetics, place of birth, skilled service provision, values and attitudes.

- Reinforcing factors: rewards or punishments meant to modify the behavior of the adolescent mothers, promote selfreliant skills and positive coping mechanisms.

- Enabling factors: resources required to reduce neonatal morbidity and mortality; identify programs supporting neonatal health, immunizations, health education, availability of and accessibility to resources, finances and regular checkups.

Teaching aids: posters, flip charts

Method of teaching: interactive

The researcher explained the terminologies described above in relation to neonatal morbidity and mortality and asked the respondents to list at least 5 factors in each category while demonstrating understanding of the factors listed.

Evaluation: question and answer session, clarifications, respondents' understanding of the topic.

Plan of action: Respondents to identify more factors from parents or guardians and categorize them starting with the most pressing factors that require immediate actions and solutions and share with group members in the following session

During experience sharing regarding danger signs in pregnancy, more than half of the respondents gave similar views, noting that the information they received from the health care providers was inadequate and that most times it was assumed that the adolescent mothers knew. "Have you been taught these things? They are not new" a health care provider would ask. The respondents felt they needed to be understood and be explained well so as to understand. "During the visit, my book was taken and ticked; I did not know what the ticks were for." One respondent said. This was echoed by several others who said that they just carried the books because they were told to do so each time they came to the clinic. "The nurses mentioned many things: headache, stomach pains, bleeding and pain in the legs among others but they did not tell us the effects and what to do before reaching the hospital". They respondents complained.

On maternal nutrition, the respondents said that they were told to use eggs, liver and fruits but they were not explained the reasons. Never the less, they did not eat them because they could not afford. "From whom shall we borrow money and yet we are being chased away from home? So we ate what was available. The respondents reported that they would be issued with medicines but no explanations, so many of them ever used to take them because they gave then abdominal upset.

The respondents also reported that unlike this method, in the clinic, all the teaching was done once only on first visit, such that they could hardly comprehend. As a result, they could boycott the sessions. In any case, they said that they were never comfortable sitting with older mothers. They said that sometimes somethings were done publicly yet they carried stigma. eg 'calling one's name to be tested HIV' so they could not come the following visit.

With regard to birth preparedness and complication readiness, they were never explained how, except buying baby clothes that some ladies were selling at the hospital of which some people could not afford. 'Ensure you buy baby's clothes' They would be told. Yet this was against some cultures to buy baby's clothes before the baby was born. On cord care, one respondent said, "it was so scaring for me. For the two babies I have had, my mother in-law has been washing them and treating the cord. I know nothing". Others said that they had been given or asked to buy methylated spirit to clean with. However, a few found it ok to leave the task to their mothers and grandmothers. But in these sessions, they were explained how to manage the cord using chlorhexidine or clean tab water and the effects of poor cord care. 
They reported having been told about exclusive breastfeeding for six months but the information collected from their friends indicated that nobody followed up to see if it was done. So, some mothers went ahead and gave porridge or cow's milk because the babies were crying of hunger. They also said that it was hard for girls going back to school because even if they expressed the milk, there was no place to keep. During the sessions, the respondents were explained how to express the milk and preserve using the locally available means but they were also advised to explore other possible options depending on set up.

Concerning social support system, they said this 'some of our parents are too harsh on us, sometimes getting pregnant is accidental, yet they treat it as an outcast. They don't understand, so they chase us away and yet they know that 'there is nowhere else we can go'. We are therefore forced to live in bad places. So, babies are born in dirty places. Some babies fall sick and die while some girls flush out.

The question of abandoning babies was discussed at length but all depended on how one would be treated after giving birth but the agreement was that the mothers would take care of their babies. The mothers were explained the importance of motherhood, bonding and their effects on the growth and development of the neonate. However, the challenge would be how to take care of them in the wake of unemployment and poverty but they were encouraged to think of simpler ways of making ends meet.

When it came to neonatal care practices and neonatal health seeking behaviors, the decisions were all taken by older mothers and fathers. The adolescent mothers had no place or say. The researcher explained the pros and cons of the actions as leading to negligence and lack of parental responsibilities. After sharing experiences from subsequent mothers, the first timer mothers realized the need to take responsibility instead of shifting it to grandmothers. At this juncture, neonatal danger signs were explained and how to identify and manage them. The mothers were explained the importance of vaccines and encouraged to have their babies immunized as soon as they were born. They were also explained the possible danger of giving birth at home and therefore encouraged having their babies in a health facility.

\section{Evaluation of the effectiveness of the health education intervention}

At two and four weeks after childbirth, each adolescent mother who participated in the study was asked to bring her baby for checkup for any emerging issues. At this time, the mothers were also assessed for coping mechanisms. Those with issues once identified were helped by the researcher or the counselor to navigate around the issue and solve it. Most mothers had this to say about the intervention:

- That it was an 'eye -opener' to information they did not know.

- That the separation from older mothers helped them to open up and share with the peers. 'I wish there would be such a clinic where we are attended to separately'. One of them said.

Those who gave birth at home and were followed up by the community health volunteers appreciated the service and promised to sensitize others. Each mother was asked to rate the intervention strategy on a $0-10$ scale with 0 being no score and 10 the highest score. Eighty-five percent (85\%) of the respondents gave a score of above 5/10 while $15 \%$ gave a score of less than 5/10. The overall consensus was that it was worthy trying it in other hospitals because it would help the adolescent mothers and save the neonates.

\section{RESULTS}

Demographic Findings

\section{age in years}
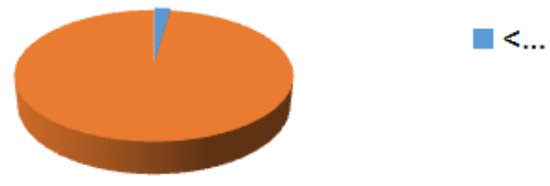

Fig-1: Respondents' age

From figure $1,97.8 \%$ of the respondents were aged between $16-19$ years while only $2.2 \%$ were aged less than 15 years. 
Anne Wawire Kabimba et al; South Asian Res J Nurs Health Care; Vol-2, Iss-3 (May-June, 2020): 62-70

Table-1: Illustrates the risk factors implicated in neonatal morbidity and morality

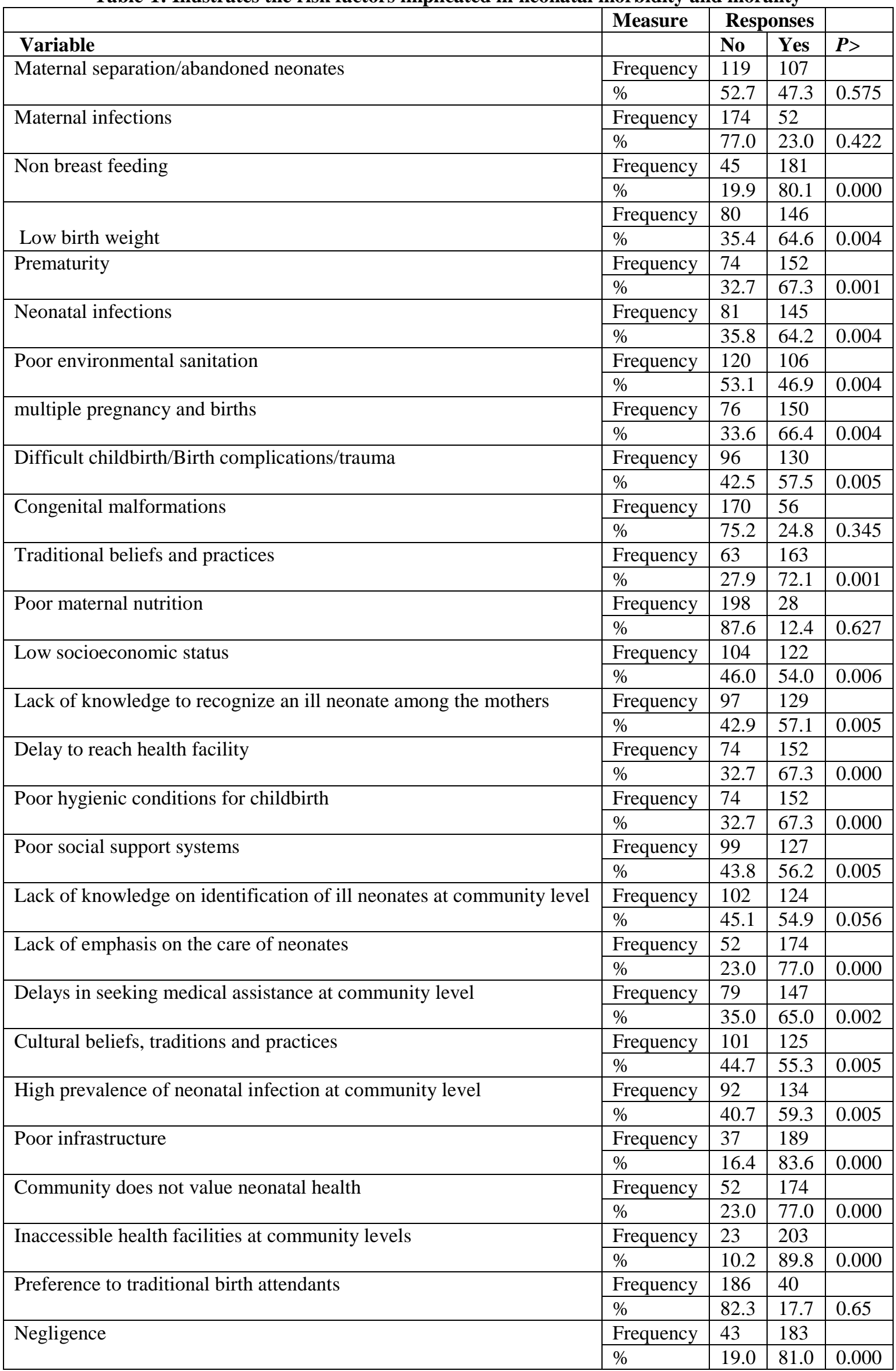




\section{DISCUSSION}

According to the findings of this study, most of the adolescent mothers were aged between 16 and 19 years with most of them married. This concurred with a study by Omedi [23], in which it was reported that adolescent mothers aged 15-18 years were more likely to conceive and get married compared to their counterparts above 19 years. According to UNICEF [24], $23 \%$ of young mothers gave birth by age 18 and that the neonatal death rate in this age group remained $27 \%$ for the under 20 years as compared to $21 \%$ among mothers aged above 20 years. This meant that the adolescent mothers were at 1.3 time's higher risk of losing their neonates.

The low socio-economic status coupled with ill-equipped knowledge to care for the neonate and unemployment contributed greatly to neonatal morbidity and mortality as the adolescent mothers were unable to support self and the neonates. This was supported by a study carried out in Malawi in which it was found that most adolescent mothers were unable to meet the needs of their babies $[25,26]$.

A variety of risk factors to adolescent neonatal morbidity and mortality were addressed in details in this study. The glaring ones included; Inaccessible health facilities at community levels as reported by $89.8 \%$ (pv 0.000 ) respondents. This was addressed also in a report by WHO [1] on 'reaching every newborn national 2020 milestones' in which every country was challenged to work out modalities of improving accessibility to health facilities. Consequently, community involvement and neonatal quality care practices could not be underestimated. Negligence was named as the second cause of neonatal morbidity and mortality in Busia at $81 \%$, (pv0.000). The adolescent mothers abandoned their babies or left them under the care of their old grandmothers. These grandmothers fed these neonates on anything in form of liquid. This led to malnutrition and subsequent deaths. Non-breast feeding was echoed by $80.1 \%$, (pv0.000) of the respondents as a major cause of neonatal deaths in Busia. Mari et al. [27] agrees with this finding. In their study, they found out that babies who were partially breastfed were at the risk of mortality three times higher than the breastfed ones while those who never breastfed were at a 14-fold higher risk of dying. Therefore, there was need to educate the adolescent mothers on the importance of early initiation and exclusive breastfeeding. Similarly, in an article by Dr. Nigel Rollins of WHO, it was noted that non -breastfed babies stood a higher risk of dying or even developing infection [28]. Cristiano et al. [29] is also in agreement by reporting that, countries with the lowest breastfeeding practices are at higher risk of neonatal mortality rates.

Lack of emphasis on the care of neonates by the social structure coupled with poor social support system was a major concern for neonatal deaths. This was reported by $77 \%$ (pv 0.000) respondents. This is reflected in an article by Nigel Collins [28] in which he was concerned about the threat by Poor government policies, lack of community support for the mothers and of course the formula milk preparations that seemed to replace breastfeeding.

Still, this study found out that the level of education did not make any significant difference as a risk factor to neonatal mortality. This contrasts the information by UNICEF on maternal and newborn health disparities in Kenya [25] in which statistics showed that, neonatal mortality rate was higher among mothers with higher education levels as compared to those with no education at all; $25: 21$.

Generally, one would agree with Gitobu et al. [17] who concluded that neonatal mortality still remains a problem even with free maternal health care provision whose goal was to reduce pregnancy and childbirth related neonatal deaths. It was interesting to listen to the adolescent mothers airing their views, concerns, sentiments and dilemmas freely to each other. The suggestions of how they would like to be handled left no doubt but desire to change the mode of antenatal care. Probably this would reduce teen pregnancy and subsequent neonatal morbidity and mortality. These findings agree with those in a study carried out by Farzaneh et al. [30] on the effectiveness of group counseling and health education to antenatal adolescent mothers, where it was reported that women of different ages wished to be attended to separately in view of their unique needs. Further still, age-specific antenatal care proved very vital. In Kenya and by extension Busia, many strategies to reduce neonatal morbidity and mortality have been developed but apparently do not consider the unique needs of the adolescent mothers separately. This still left the adolescent mothers at a high risk of losing their neonates.

\section{CONCLUSION}

In conclusion, this study found out that neonatal morbidity and mortality among neonates born to adolescent mothers in Busia County Referral Hospital were influenced by multiple risk factors including but not limited to poor social support system, non-breast feeding, poor infrastructure and inaccessibility to health facilities, cultural beliefs and practices and negligence.

It is also very clear that the poor infrastructure played a major role in neonatal mortality as many adolescent mothers would not access the health facilities. Same to negligence, where the mothers abandoned their babies or left 
them under the care of their old grandmothers probably under pressure or in desperation. Overly, the neonatal morbidity and mortality remains high.

\section{RECOMMENDATION}

The adolescent mothers need space and age- specific care tailored to their needs and therefore the need to step up and intensify the health education strategies for the adolescent mothers and the community. There is need for the individual adolescents, the health care provider and the community to harmonize the neonatal care practices tailored to adolescence level of understanding.

Study limitations: Inaccurate record keeping, limited finances,

Competing interests - The author has no competing interests. The content in this study is the author's original research work.

$$
\text { Funding - self }
$$

\section{Consent for publication}

Individual data was not presented therefore not applicable

Author's information: This article is a revised version of a sub-section of my PhD thesis (Specific Objective 1).

\section{REFERENCES}

1. World Health Organization. (2014). Global status report on noncommunicable diseases 2014 (No. WHO/NMH/NVI/15.1). World Health Organization.

2. Akella, D., \& Jordan, M. (2011). Impact of social and cultural factors on teenage pregnancy Journal of Health Disparities Research and Practice, Vol. 8, issue 1,Pg 41-62

3. Anafi, A. (2012). Understanding Maternal Health-Care Seeking Behavior in Low income Communities in Accra, Ghana; UMI dissertation publishing,

4. Ersdal, H.L., Mduma, E., Svensen, E., Perlman, J.M (2012). Birth Asphyxia is the Major Cause of Early Neonatal Mortality in a Rural Hospital in Tanzania. Pediatrics 2012, DOI:10.1542/peds.2011- 3134

5. Desalegn, T. H., Tadesse, A. A., Zelalem, B. M. (2013). Determinants of Neonatal Mortality in Ethiopia: A Case Control Study

6. Mari, G., Bursac, Z., Goedecke, P. J., \& Dhanireddy, R. (2018). Factors Associated With Improvements in Mortality and Morbidity Rates of Very-Low-Birth-Weight Infants: a Cohort Study. Global pediatric health,5, $2333794 X 18765366$.

7. Bokade, C. M., \& Meshram, R. M. (2018). Morbidity and mortality patterns among outborn referral neonates in central India: Prospective observational study. Journal of Clinical Neonatology, 7(3), 130.

8. Pandya, N. K., \& Mehta, K. G. (2018). Study of morbidity and mortality profile in special care newborn unit at tertiary care teaching institute in Vadodara, Gujarat, India. International Journal of Contemporary Pediatrics, 5(5), 1763.

9. Ravikumar, S. A., Elangovan, H., Elayaraja, K., \& Sunderavel, A. K. K. (2018). Morbidity and mortality profile of neonates in a tertiary care centre in Tamil Nadu: a study from South India. Int J Contemp Pediatr, 5, 377-82.

10. Kabwijamu, L., Waiswa, P., Awooya, V.K., Okuga, C.M. K., Nalwadda., Nabiwemba, E.L (2016) Newborn Care Practices among Adolescent Mothers in Hoima District, Western Uganda

11. Birju, A. S., \& James, F. P (2014). Neonatal Sepsis; an Old Problem with New Insights. Virulence, 5(1):170-178

12. Hibstu, D.T., Ayele, T.A. and Mengesha, Z.B (2014). Determinants of Neonatal Mortality in Ethiopia: A Case Control Study, 2013. Open Access Library Journal, 1: e880.

13. Kakaire, O., Kaye, D. K., \& Osinde, M. O. (2011). Male involvement in birth preparedness and complication readiness for emergency obstetric referrals in rural Uganda. Reproductive health, 8(1), 12.

14. Jain, Y., Bansal, M., Tiwari, R., \& Kasar, P.K. (2013). Causes of Neonatal Mortality. A community Based Study Using Verbal Autopsy Tool. Nalt J Community Med; 4(3):498-502

15. Mmbaga, B. T., Lie, R. T., Olomi, R., Mahande, M. J., Kvåle, G., \& Daltveit, A. K. (2012). Cause-specific neonatal mortality in a neonatal care unit in Northern Tanzania: a registry based cohort study. BMC pediatrics, $12(1), 116$.

16. MoH, U. (2010). Health sector strategic plan III 2010/11-2014/15.

17. Gitobu, C.M,. Gichangi, P.B., \& Mwanda W.O. (2017). Causes of neonatal mortality two years before and after the implementation of a free maternal health care policy in Kenyan public health facilities. East African Medical Journal, Vol 94, Issue 5

18. Boundy, E. O. (2015). Determinants of Global Maternal and Neonatal Morbidity and Mortality. Doctoral dissertation, Harvard T.H. Chan School of Public Health 
19. Chang, H. H., Larson, J., Blencowe, H., Spong, C. Y., Howson, C. P., Cairns-Smith, S., ... \& Walani, S. (2013). Preventing preterm births: analysis of trends and potential reductions with interventions in 39 countries with very high human development index. The Lancet, 381(9862), 223-234.

20. Kozuki, N., Lee, A. C., Silveira, M. F., Sania, A., Vogel, J. P., Adair, L., ... \& Humphrey, J. (2013). The associations of parity and maternal age with small-for-gestational-age, preterm, and neonatal and infant mortality: a metaanalysis. BMC public health, 13(S3), S2.

21. Girum, S. (2014). Strengthening the new born care capacity of health centers in Amhara region, Ethiopia. AMREF Health Africa International Conference, Nairobi, Kenya

22. Jalemba, A., Okello, D., Murithi, G... (2015). Delivery outcomes and patterns of morbidity and mortality for neonatal admissions in five Kenyan hospitals. Journal of Tropical Pediatrics (0): 1-5.

23. Ramaiya, A., Kiss, L., Baraitser, P., Mbaruku, G., \& Hildon, Z. (2014). A systematic review of risk factors for neonatal mortality in adolescent mother's in Sub Saharan Africa. BMC research notes, 7(1), 750.

24. Ministry of Health, Government of Kenya. (2016). Kenya Reproductive Maternal Neonatal Child and Adolescent Health (RMNCAH) Investment Framework

25. Kumar, M., Huang, K. Y., Othieno, C., Wamalwa, D., Madeghe, B., Osok, J., ... \& McKay, M. M. (2018). Adolescent pregnancy and challenges in Kenyan context: Perspectives from multiple community stakeholders. Global Social Welfare, 5(1), 11-27.

26. Azevedo, E. P., \& Kumar, V. (2012). Rheological, water uptake and controlled release properties of a novel selfgelling aldehyde functionalized chitosan. Carbohydrate polymers, 90(2), 894-900.

27. Sankar, M. J., Sinha, B., Chowdhury, R., Bhandari, N., Taneja, S., Martines, J., \& Bahl, R. (2015). Optimal breastfeeding practices and infant and child mortality: a systematic review and meta- analysis. Acta paediatrica, 104, 3-13.

28. Nigel, R. (2016). Breastfeeding could prevent 800,000 child deaths, Lancet says, Two-part lancet breastfeeding series

29. Cristiano, P. (2013). Philipcristiano/t2g. py. GitHub Gists.

30. Soltani, F., Aghababaei, S., Samiei, V., \& Roshanaei, G. (2018). The effectiveness of group counseling on prenatal care knowledge and performance of pregnant adolescents in a Kurdish region of Iran. International journal of adolescent medicine and health. 